УДК 621.313.04:621.315.61

\title{
КОНТРОЛЬ ПРОПИТКИ - ЭФФЕКТИВНЫЙ ФАКТОР ПОВЫШЕНИЯ НАДЕЖНОСТИ ЭЛЕКТРОДВИГАТЕЛЕЙ ГОРНОДОБЫВАЮЩЕЙ, СТРОИТЕЛЬНОЙ И ДРУГИХ ОТРАСЛЕЙ ПРОМЫШЛЕННОСТИ
}

\author{
Смирнов Геннадий Васильевич', \\ smirnov@main.tusur.ru
}

\author{
Ведяшкин Максим Викторович², \\ vedyashkin@tpu.ru
1 Томский государственный университет систем управления и радиоэлектроники, Россия, 634045, г. Томск, пр. Ленина, 40.
2 Национальный исследовательский Томский политехнический университет, Россия, 634050, г. Томск, пр. Ленина, 30.

\begin{abstract}
Отказ электрической машины приводит к аварийным ситуациям, к простою оборудования и, как следствие, к высоким экономическим затратам на ликвидацию результатов отказа машины. Наибольший ущерб отечественной экономике наносит отказ электрических машин при разведке, добыче и транспортировке георесурсов в нефтедобывающей, горнорудной, угольной, химической и других отраслях промышленности, так как эти отрасли в настоящее время являются основой формирования бюджета страны. Надежность и безотказность работы этих машин в значительной степени определяется технологическими операциями пропитки и сушки обмоток, так как на этих операциях формируются важнейшие качественные характеристики обмоток: электроизоляционные, тепловые, влагостойкие и механические. Все эти свойства зависят от степени заполнения межвитковых и прикорпусных полостей обмотки пропиточным составом. В случае некачественной пропитки обмоток возможно появление дефектов в межвитковой изоляции в период хранения и транспортировки оборудования к месту эксплуатации, что неизбежно приводит к снижению надежности изоляции обмоток. Совершенствование указанных операций невозможно осуществлять без надлежащих способов неразрушающего контроля качества проведения этой операции. Поэтому разработка методов контроля качества пропитки обмоток является весьма злободневной проблемой.

Цель: показать возможность контроля распределенности пропиточного состава по обмотке по результатам измерения теплоёмкости обмоток до пропитки и после неё.

Методы: электротепловые и электромагнитные, связанные с измерением тепловых параметров обмотки и отдельных электрических величин при контроле качества пропитки.

Результаты. Рассмотрен электротепловой способ контроля качества пропитки обмоток. Обоснованы физические принципы контроля качества пропитки, и приведен вывод основных критериев оценки качества указанной технологической операций. Приведена схема прибора контроля, и рассмотрен принцип его работы. Произведен анализ погрешностей предложенного способа контроля.
\end{abstract}

\section{Ключевые слова:}

Обмотка, пропиточный состав, система управления, преобразователь, теплоёмкость, сопротивление, время, генератор, триггер, счетчик.

\section{Введение}

Безотказность электрических машин - один из важнейших показателей надежности, так как отказ двигателя приводит к аварийным и часто к опасным для здоровья и жизни людей факторам. Наибольшую опасность для людей представляют отказы электродвигателей в производствах горнодобывающей, нефтяной, газовой и других производствах сырьевой промышленности [1]. Именно в этих отраслях промышленности электрические машины широко используют в качестве электроприводов бурильных установок [2], шахтных вентиляционных устройств [3], в погружных электроцентробежных насосах при добыче нефти [4], в лебедках и других транспортных средствах [5], где их отказ может привести к возникновению чрезвычайных ситуаций и даже к гибели людей. Caмым ненадежным узлом электрической машины является изоляция их обмоток $[1,6]$. Показатели надежности изоляции обмоток электрических машин закладываются в процессе их производства и зависят от качества изоляции обмоточного провода, от намоточного оборудования, технологии пропитки и сушки обмоток [7-12]. При этом в процессе намотки обмоток происходит снижение показателей их надежности из-за образования многочисленных дефектов в эмалевой изоляции проводов, обусловленных вытяжкой провода, растрескиванием изоляционной пленки обмоточных проводов, образованием в ней сдиров и проколов. Операция пропитки обмоток, наоборот, способствует повышению качества изоляции обмоток, так как на этом этапе пленкой пропиточного состава скрываются дефекты в витковой, межфазной и корпусной изоляции. При этом качество изоляции пропитанных обмоток зависит не только от свойств самого пропиточного состава, но и от того, какое количество этого состава проникло в полости обмоток, и как он распределился по указанным полостям. В результате пропитки обмоток повышаются не только их электроизоляционные свойства, но и их теплопроводность, влагостойкость, монолитность 
и другие характеристики, повышающие надежность изоляции обмоток.

При некачественной пропитке, когда степень заполненности межвитковых и прикорпусных полостей пропиточным составам низка, часть существующих в обмотке пустот остается незаполненной пропиточным составом. В результате этого усугубляется процесс проникновения влаги и пыли в обмотки электрических машин, что приводит к ускоренному старению изоляции обмоток и к значительному повышению вероятности отказа изоляции указанных обмоток [7-14].

Повышение качества изоляции обмоток невозможно осуществить без совершенствования технологии пропитки и сушки. Совершенствование же этих операций, оперативное устранение технологических причин, приводящих к некачественной пропитке и сушке, невозможно реализовать без разработки и внедрения неразрушающих методов контроля качества проведения указанных технологических операций. Попытки создания точных и информативных способов контроля качества пропитки предпринимались в работах ряда исследователей [15-29]. В основу контроля в этих работах было положено измерение ёмкости обмоток относительно магнитного сердечника до пропитки и после неё. Такой контроль позволяет оценить только качество пропитки прикорпусных полостей обмотки. Однако этим способом невозможно определить наиболее важный параметр - степень заполнения пропиточным составом межвитковых полостей обмотки, а также нельзя оценить, как распределился пропиточный состав по фазам обмотки.

Цель настоящей работы - устранение недостатков вышеназванных способов контроля пропитки, повышение точности и информативности контроля.

\section{Статистика отказов электродвигателей в различных} отраслях промышленности и их причины

В настоящее время электропривод занимает доминирующее положение практически во всех промышленных и многих транспортных механизмах. Согласно статистике, электроприводом оснащены примерно 85 \% всех двигательных и силовых механизмов (насосы, компрессоры, вентиляторы, станки, разнообразные технологические машины, бытовая техника и др.). Асинхронные двигатели (АД) стали изделием массового применения, и на сегодня они потребляют около 75 \% вырабатываемой во всем мире электроэнергии [25].

Электрические двигатели участвуют во многих сложных и ответственных технологических процессах и операциях. Отказ в их работе может повлечь за собой огромные убытки предприятия изза простоя технологического оборудования, а также несет угрозу безопасности жизни людей. Такие убытки могут во много раз превышать стоимость самого электродвигателя, вышедшего из строя. Специфические и тяжелые условия эксплуатации приводят к снижению надежности и долговечности электродвигателей. Окружающая среда, в ко- торой функционирует электрическая машина, может значительно отличаться от нормированной для нормальной работы электродвигателей. В частности, в горнодобывающей, строительной и нефтегазовой промышленностях присутствие в вентилируемом электродвигателем воздухе агрессивных сред, паров кислот и щелочей, токопроводящей и не токопроводящей пыли, а также других механических включений ведут к преждевременному износу, а то и к выходу из строя как витковой, так и корпусной изоляции, что приводит электродвигатель в негодность. Технико-экономическое совершенство и эксплуатационная надежность работы электрических машин в значительной степени зависят от изоляции. Если учесть то, что стоимость изоляции составляет около половины стоимости всех материалов машины, становится понятным то большое внимание, которое уделяется специальным вопросам, связанным с изготовлением и диагностикой состояния изоляции электрических машин. Асинхронные двигатели нередко работают в весьма тяжелых условиях при неудовлетворительном обслуживании или совершенно без какого-либо ухода. Примерно $30-35$ \% отказов происходит вследствие недостатков конструкции и технологии производства двигателей. Лишь 10-12\% двигателей выходят из строя вследствие естественных процессов старения и износа. Статистика обнаруживает резкие колебания в уровне аварийности и сроке службы двигателей в различных отраслях промышленности. Среднегодовой выход двигателей в капитальный ремонт составлял: в строительстве - $54 \%$, в горнодобывающей промышленности - $29 \%$, в промышленности стройматериалов - $25 \%$, в пищевой промышленности $-24 \%$. В то же время в химической промышленности, где условия работы двигателей также достаточно неблагоприятны, средний выход в капитальный ремонт в год составил лишь $9 \%$, в черной металлургии - $13 \%$. На некоторых шахтах Кузбасса электродвигатели служат в среднем всего 6-7 мес. В условиях химической промышленности средний технический ресурс двигателей серии BAO до первого капитального ремонта составляет 60-80 тыс. ч, в то время как на угольных шахтах только 5-6 тыс. ч, а для отдельных приводных механизмов даже около 2 тыс. ч. Распределение повреждений по отдельным узлам асинхронных двигателей изменяется в зависимости от условий их применения, однако наибольшее число повреждений приходится на обмотку статора. В среднем изза повреждений обмоток двигателей происходит $85-95 \%$ отказов, 3-8\% отказов происходит вследствие повреждений подшипников [30]. По характеру повреждений обмоток отказы асинхронных двигателей единой серии распределяются следующим образом: межвитковые замыкания $93 \%$, повреждения междуфазовой изоляции $5 \%$, пазовой изоляции - $2 \%$ [26]. Таким образом, в подавляющем большинстве случаев причиной отказов является повреждение межвитковой изо- 
ляции, типичное для всыпных обмоток. Повреждения междуфазовой и пазовой изоляции обычно возникают как следствие межвитковых замыканий и представляют развитие последних. Для асинхронных двигателей общепромышленного применения изменение интенсивности отказов в функции времени имеет довольно типичный характер, обнаруживая отчетливые периоды приработки, нормальной эксплуатации и износа. Правильная форма кривой интенсивности отказов обусловлена тем, что преобладающей причиной отказов являются межвитковые замыкания в обмотке статора и, таким образом, в большинстве случаев отказы однотипны по своему происхождению [31]. Обобщая полученные данные о повреждениях изоляции, можно назвать наиболее характерные из них: короткое замыкание на корпус, короткие витковые замыкания, пробой и обугливание изоляции, обрыв обмотки статора. Наиболее частое сочетание встречающихся видов повреждений это пробой и обугливание изоляции с витковым коротким замыканием и повреждением провода. Такое сочетание видов повреждений имеют $51,2 \%$ из всех вышедших из строя и обследованных электродвигателей. Обугливание изоляции в сочетании с пробоем наблюдается у 10,2 \% двигателей, а обугливание изоляции в сочетании с витковым коротким замыканием и пробоем - у $13,1 \%$. В «чистом» виде пробой изоляции имеет место у $4,8 \%$, обугливание изоляции - у $13,5 \%$, витковое короткое замыкание - у 4,3 \% электродвигателей. Лишь $29 \%$ электродвигателей имели механические повреждения без повреждения обмотки. Кроме этого, по данным некоторых исследований, пробой на корпус наблюдался у $16 \%$, а сгорание обмоток - у $46 \%$ электродвигателей. Особенно опасны отказы двигателей вследствие пробоя изоляции в горнодобывающей промышленности, в частности в угольных шахтах. Такие отказы могут повлечь возгорания и взрывы угольной пыли и привести к гибели людей. Все это говорит о том, насколько высокими должны быть требования к технологии изготовления обмоток электродвигателей. Для этого необходимы средства и методы контроля и диагностирования изоляции обмоток в процессе их изготовления. Основное количество повреждений витковой изоляции обмоток происходит в процессе их намотки [26]. Во время эксплуатации изоляция электрооборудования, в том числе и электрических машин, подвергается различным воздействиям, под влиянием которых происходит старение изоляции, т. е. необратимое ухудшение еe свойств. Для изоляции электрических двигателей характерным является образование местных дефектов (например, трещин), т. е. существенное ухудшение ее электрических свойств на отдельных небольших участках. К причинам, вызывающим повреждения изоляционных материалов, относятся тепловые и электрические поля, величины механических нагрузок, запыленность и влажность окружающей среды. Качественная пропитка позволяет создать систему изоляции, устойчивую к действию указанных эксплуатационных воздействий. Это обусловлено тем, что операция пропитки обмоток является многоцелевой и приводит не только к скрытию дефектов в витковой, межфазной и корпусной изоляции, но и вызывает значительное улучшение тепловых, механических, влагозащитных и других свойств изоляции обмотки [25]. Во время работы оборудования его изоляция испытывает эти воздействия одновременно, при этом возможно взаимодействие, т. е. одновременно приложенные воздействия могут вызывать старение изоляции с иной скоростью, нежели приложенные поочередно. Каждый из перечисленных ранее видов воздействия может оказаться в определенных условиях основным, определяющим процесс старения изоляции или ее части, в этом случае данному виду воздействия будет соответствовать определенный характер старения изоляции и вызываемые этим старением дефекты. Тепловое старение изоляции является следствием постепенного химического изменения входящих в ее состав органических веществ. Возможны другие условия теплового старения изоляции - сравнительно кратковременное действие температур, существенно превышающих допустимые рабочие температуры. Такие условия возникают, как правило, при местных перегревах: замыкание ряда элементарных проводников в пазовой части стержня с быстрым ростом температуры в месте замыкания, излом проводника со случайным контактом в месте излома.

Основными факторами действия на изоляцию электрических машин окружающей среды являются: действие окружающего изоляцию газа (например, воздуха); действие влаги, содержащейся в воздухе, газе или попадающей на изоляцию в виде жидкости (например, попадание влаги извне при действии устройств пожаротушения, при небрежном хранении статора и т. п.). Кроме того, возможно абразивное действие пыли, содержащейся в воздухе. Действие окружающего изоляцию газа сказывается в основном на процессах теплового и электрического старения изоляции. Действие на изоляцию крупных металлических частиц и предметов, попавших в двигатель извне или выпавших из различных его узлов, с некоторым допущением также может быть отнесено к действию окружающей среды. Увлажнение изоляции при работе машины возможно лишь при попадании воды на обмотку. Увлажнение изоляции от действия влажного воздуха возможно только тогда, когда машина не работает (во время транспортировки, монтажа, длительного ремонта и т. п.). При этом разные части изоляции увлажняются по-разному в зависимости от материала, из которого они сделаны, и технологии пропитки. Современная пропитка обмоток термореактивными компаундами, не имеющая дефектов при высоком коэффициенте пропитки, практически не подвержена объемному увлажнению. В ней при правильном ее изготовлении мало пор, проникая в которые влага могла бы сни- 
зить ее электрическую прочность. Термореактивные компаунды мало гигроскопичны, и процесс их увлажнения идет весьма медленно. Значительно более интенсивно идет процесс поверхностного увлажнения, однако такое увлажнение легко устраняется подсушкой изоляции на воздухе даже без нагрева. Только при наличии дефектов увлажнение может существенно сказаться на пробивном напряжении изоляции. Такими дефектами могут быть трещины, образовавшиеся при укладке стержней и подгонке головок из-за неправильной формы лобовых частей или нарушения технологии укладки. Другим дефектом может явиться недостаточная пропитка изоляции и плетеного стержня термореактивным компаундом. Непрерывная компаундированная изоляция, не имеющая дефектов, практически также не подвержена объемному увлажнению ни под действием обычной влаги воздуха, ни при кратковременном смачивании водой: пропитка компаундом хотя бы внешних слоев изоляции делает ее мало гигроскопичной. У такой изоляции (как и термореактивной) возможно главным образом поверхностное увлажнение. Механическим воздействиям изоляция подвергается как во время изготовления, так и во время эксплуатации электрической машины. Механические воздействия приводят к возникновению в изоляции деформаций растяжения, сжатия, изгиба, смятия, кручения, а также к трению поверхности стержней о прилегающие к ним детали. При неблагоприятных обстоятельствах это приводит к появлению дефектов изоляции в виде трещин, складок, ее расслоения и местного уменьшения толщины. Уровень механических воздействий с ростом мощности двигателей непрерывно возрастает, и увеличивается опасность механического повреждения изоляции в случае малейших конструктивных или технологических недоработок, упущений при монтаже. В связи с этим механические повреждения изоляции являются наиболее характерной причиной дефектов, выявляемых в машинах, находящихся в эксплуатации. Термомеханические воздействия возникают при тепловых циклах (нагревании и охлаждении обмотки) в основном вследствие разницы в температурах и коэффициентах линейного расширения меди, активной стали и изоляции, а также наличия значительного терния между поверхностью стержня и стенками паза. Вследствие указанных причин при изменении тока в обмотке и соответствующем изменении температуры токоведущей части стержня и длины последней (расширении или сжатии) в изоляции возникают напряжения растяжения или сжатия, усугубляемые тем, что перемещения стержня в пазу происходят с усилием. При термореактивной изоляции и уплотнении стержня в пазу боковыми пружинящими прокладками смещения меди и изоляции относительно стали сердечника практически одинаковы, т. е. изоляция не смещается относительно токоведущего стержня, а образует с ним комплекс с некоторым общим коэф- фициентом линейного расширения. Термомеханические напряжения при большом числе циклов нагрева и охлаждения существенно влияют на состояние термореактивной изоляции и при сочетании неблагоприятных условий, в частности при недостаточно совершенной ее системе, могут привести к отказу изоляции. Анализ всех известных способов поддержания эксплуатационной надежности изоляции АД, основными из которых являются ее капитальный ремонт, техническое обслуживание, периодическая диагностика, обеспечение надежной защитой, показывает, что основными мероприятиями, способствующими созданию базового ресурса работы изоляционной системы, являются ее пропитка и сушка специальными диэлектрическими составами [26]. Обмоточно-изолировочные работы являются важнейшими при ремонте. Это обусловлено тем, что правильный выбор значений конструктивных параметров обмотки обеспечивает нормируемые значения рабочих и энергетических характеристик электродвигателя, а качественное выполнение работ способствует отсутствию дефектов в эмалевом покрытии проводников. В практике эксплуатации электрооборудования в сельском хозяйстве известны случаи, когда после полной или частичной перемотки АД не подвергались операциям пропитки и сушки. При этом ЭД сохраняли работоспособное состояние в течение некоторого времени. Однако вследствие воздействия агрессивных факторов эмалевое покрытие проводов сравнительно быстро повреждалось, и электродвигатель выходил из строя. Таким образом, эксплуатационная надежность изоляции обмотки после обмоточно-изолировочных работ низка. В практике электромашиностроения для повышения надежности изоляционных конструкций низковольтных электродвигателей используется пропитка и сушка их обмоток. Сушка перед пропиткой необходима для удаления влаги из пор изоляции, препятствующей проникновению лака в тело обмотки. Сушку перед пропиткой требуется выполнять еще и потому, что при пропитке лаки и компаунды быстрее и глубже проникают внутрь нагретых обмоток вследствие разрежения воздуха в капиллярах, которое возникает при нагревании обмоток. Следует также отметить, что чем выше температура, тем быстрее происходит удаление влаги из обмоток. Сушка до пропитки может осуществляться с использованием следующих методов: конвекционного, токового, терморадиационного, индукционного, электроосмоса, вакуумного, скоростного электротермовакуумного. Одним из путей повышения надежности изоляции обмоток является обоснование режимов технологического процесса ее пропитки и сушки на основе оптимизации этих процессов, которую невозможно осуществить без надлежащих способов и устройств контроля пропитки. В процессе проведения технологических операций изготовления обмоток электродвигателей измеряются некоторые величины, которые являются частными показателями каче- 
ства. К ним относится дефектность изоляции провода, возникающая при намотке, коэффициент пропитки и степень полимеризации пропиточного состава при сушке после пропитки [25]. Каждый из частных показателей качества является характеристикой успешности выполняемых операций технологического процесса. Основной интерес представляет технический аспект использования тех или иных показателей качества. В настоящее время для диагностики изоляции электродвигателей распространение получили тестовые средства диагностики и контроля, работающие по принципу посылки специального сигнала с последующей его обработкой, а также различные электрические приборы. К диагностирующим приборам, обеспечивающим минимальные затраты при осуществлении процесса оценки состояния изоляции, относятся ручные автоматические приборы и устройства периодического контроля. К техническим средствам диагностики и контроля обмоток электродвигателей относятся электромеханические, цифровые и электронные омметры, измерительные мосты, специальные устройства для измерения добротности и емкости. Наибольшее распространение в последнее время получили аналоговые электромеханические и электронные цифровые приборы. Иногда для измерения емкости применяются измерительные мосты. Все показатели качества можно разделить на электрические и неэлектрические величины. $К$ электрическим величинам относится сопротивление обмотки, её индуктивность, межвитковая ёмкость, ёмкость обмотки относительно магнитного сердечника и т. п. $\mathrm{K}$ неэлектрическим величинам относится глубина проникновения лака в обмотку, лакопоглощение, влагоудаление, коэффициент пропитки и т. п. Результаты исследований позволяют использовать для оценки каждого этапа технологического процесса следующие показатели: дефектность, протяженность дефектов, коэффициент пропитки и степень полимеризации пропиточного состава.

\section{Теоретическое обоснование}

\section{электротеплового контроля}

Рассмотрим сущность предлагаемого электротеплового способа контроля.

В обмотках статоров электрических машин, соединенных чаще всего в звезду, для более полной характеристики качества пропитки необходимо знать не только средний коэффициент пропитки контролируемой обмотки, но и как пропиточный состав распределен по фазам обмотки. В способе [31] показана последовательность измерений и расчетов, позволяющих определить только усредненный коэффициент пропитки полостей двух фаз обмотки, но не позволяет определить распределенность упомянутых коэффициентов по фазам обмотки. Покажем, как можно определить коэффициенты пропитки не только полостей двух фаз обмотки, но и коэффициенты пропитки каждой из фаз обмотки.
Введем следующие обозначения: $K_{i 12}, K_{i 13}, K_{i 23}-$ коэффициенты пропитки двух фаз обмотки, соответственно 1-2, 1-3, 2-3, связанных в звезду. Для упрощения описания рассмотрим сущность предлагаемого способа на примере определения коэффициента пропитки полостей любых двух фаз обмотки, например фаз 1-2, а потом обобщим полученные результаты для всех остальных фаз.

Коэффициент пропитки двух фаз обмотки можно записать в виде:

$$
K_{i 12}=\frac{m_{12}}{m_{012}},
$$

где $m_{12}$ - суммарная масса пропиточного состава в полостях фаз 1-2 обмотки; $m_{012}-$ предельная масса, которую можно разместить в полостях упомянутых двух фаз обмотки при их 100 \% -м заполнении. Величина $m_{012}$ в выражении (1) может быть определена расчетным путем по формуле:

$$
m_{012}=d_{\mathrm{c}} V_{012} \text {. }
$$

В формуле (2) общий объем полостей в двух фазах обмотки $V_{012}$ находится из обмоточных данных статора по известной формуле:

$$
V_{012}=S_{\tilde{n}} l_{w}\left(1-\frac{\pi}{4} K_{f}\right) \cdot \frac{\partial}{2},
$$

где $S_{\mathrm{c}}$ - площадь сечения паза; $l_{w}$ - длина полувитка обмотки; $K_{f}$ - коэффициент заполнения паза проводом; $p$ - количество пазов, в которые всыпаны две фазы обмотки.

Таким образом, для определения коэффициента пропитки $K_{12}$ по формуле (1) необходимо знать величину $m_{12}$, тогда как величину $m_{012}$ можно определить с использованием формул (2) и (3). Рассмотрим, как измерить указанную величину, используя электротепловой способ, в основу которого положен принцип измерения эквивалентной теплоемкости обмотки.

Условно обмотку электротехнического изделия до пропитки можно представить в виде слоистого анизотропного тела, состоящего из медного провода, эмалевой изоляции, межвитковых воздушных полостей, корпусной изоляции, прикорпусных воздушных полостей. Обмотка всыпана в пазы массивного стального сердечника. Обмотку после пропитки и сушки также можно представить в виде анизотропного слоистого тела, только воздушные полости после пропитки и сушки заполнены пропиточным составом.

До пропитки эквивалентная теплоемкость двух фаз обмотки $C_{\text {т12 }}$ равняется сумме теплоемкостей

$$
C_{\text {д12 }}=C_{\text {пр12 }}+C_{\text {эм } 12}+C_{\text {ки12 }},
$$

где $C_{\text {пр12 }}=c_{\text {пр }} m_{\text {пр12 }}-$ эквивалентная теплоемкость провода двух фаз контролируемой обмотки; $C_{\text {эм12 }}=c_{\text {эм }} m_{\text {э12 }}$ - эквивалентная теплоемкость эмалевой изоляции провода двух фаз обмотки; $C_{\text {ки12 }}=c_{\text {ки }} m_{\text {ки12 }}-$ эквивалентная теплоемкость корпусной изоляции двух фаз обмотки; $c_{\text {пр }}, c_{\text {эм }}, c_{\text {ки }}-$ удельные теплоемкости материала провода, эмали, корпусной изоляции, соответственно; $m_{\text {п1 } 12}$, $m_{\text {э12 }}, m_{\text {ки12 }}-$ массы жилы провода, эмали и корпусной изоляции двух фаз обмотки, соответственно. 
После пропитки эквивалентная теплоемкость двух фаз обмотки $C_{\text {п12 }}$ станет равной

$$
C_{\text {п12 }}=C_{\text {пр12 }}+C_{\text {эм12 }}+C_{\text {ки12 }}+C_{\text {пс12 }} \text {, }
$$

где $C_{\text {с12 }}=c m_{12}, c$ - удельная теплоемкость пропиточного состава.

Из выражений (4) и (5) следует, что

$$
m_{12}=\frac{C_{112}-C_{\text {स12 }}}{\tilde{n}} \text {. }
$$

Из выражения (6) следует, что для определения величины $m_{12}$ достаточно измерить две величины $-C_{\text {п12 }}$ и $C_{\text {д12 }}$, и найти их разность. Если к двум фазам непропитанной обмотки подвести греющую энергию $Q_{\text {д12 }}$ и создать такие условия, чтобы потерь тепла из обмотки в окружающую среду и магнитный сердечник не было, а все тепло указанной энергии было бы потрачено только на разогрев упомянутых фаз обмотки, то, измерив приращение температуры упомянутых двух фаз обмотки $\Delta T_{\text {д12 }}$, можно было бы определить их эквивалентную теплоемкость $C_{\text {д12 }}$ согласно выражению:

$$
C_{\text {स12 }}=\frac{Q_{\text {स12 }}}{\Delta T_{\text {स12 }}} .
$$

Исключения потерь тепла из обмотки можно достичь, если время подвода $t_{0}$ энергии выбрать достаточно малым исходя из условия

$$
0,01 \tau \leq t_{0} \leq 0,013 \tau,
$$

где $\tau$ - постоянная разогрева обмотки.

Величину $\tau$ в выражении (8) можно определить по выражению (9), приведенному ниже

$$
\tau=R_{\text {тепл }} C_{\text {д.расч }},
$$

где $R_{\text {теп }}$ - расчетное тепловое сопротивление двух фаз непропитанной обмотки; $C_{\text {др.рас }}-$ расчетная эквивалентная теплоемкость двух фаз непропитанной обмотки.

Тепловое сопротивление в формуле (9) двух фаз непропитанной обмотки можно найти по формуле

$$
R_{\text {тепл }}=\frac{1}{p}\left[\frac{d_{\ni}}{S_{10 х л \pi} \lambda_{\ni}}+\frac{1}{S_{20 х л \pi}}\left(\frac{d_{\text {ки }}}{\lambda_{\text {ки }}}+\frac{d_{\mathrm{B}}}{\lambda_{\mathrm{B}}}\right)\right],
$$

где $p$ - количество пазов, в которые всыпаны две фазы обмотки; $d_{3}, d_{\text {ки }}, d_{\text {в }}$ - толщина эмалевой изоляции провода, корпусной изоляции и воздушного зазора между обмоткой и корпусной изоляцией соответственно; $S_{10 x л}=\Pi \cdot l_{w}$ - поверхность охлаждения двух фаз обмотки, периметр паза; $l_{w}$ - длина полувитка обмотки; $S_{20 x л}=\Pi \cdot l_{\Pi}$ - поверхность охлаждения двух фаз обмотки, примыкающих к корпусной изоляции; $l_{\text {п }}$ - длина паза; $\lambda_{\text {э }}$ - теплопроводность эмали; $\lambda_{\text {ки }}$ - теплопроводность корпусной изоляции; $\lambda_{\text {в }}$ - теплопроводность воздуха.

Для расчета теплового сопротивления по выражению (10) нужно знать конструктивные данные электрической машины и теплопроводности конструкционных материалов.

Греющую энергию $Q_{\text {дा12 }}$ к двум фазам обмотки можно подводить путем пропускания стабилизированного тока $I_{0}$ через провод упомянутых фаз. В этом случае величину греющей энергии можно вычислить по выражению

$$
Q_{\text {дा12 }}=I_{0}^{2} \cdot t_{0} \frac{\left(R_{\text {д12 }}+R_{\text {дp12 }}\right)}{2},
$$

где $R_{\text {д12 }}$ - сопротивление двух фаз обмотки в момент подключения к ним источника стабилизированного тока; $R_{\text {др12 }}$ - сопротивление двух фаз обмотки в момент времени $t_{0}$.

Величина $\Delta T_{\text {д12 }}$ может быть определена по изменению сопротивления провода двух фаз обмотки в процессе её разогрева стабилизированным током из выражений:

$$
\begin{aligned}
& R_{\text {д12 }}=R_{12220}\left[1+\alpha\left(T_{\text {д12 }}-20\right)\right], \\
& R_{\text {дp12 }}=R_{122020}\left[1+\alpha\left(T_{\text {дp12 }}-20\right)\right] .
\end{aligned}
$$

В выражениях (12) и (13) величина $R_{12220}$ - это сопротивление двух фаз непропитанной обмотки при температуре $T=20{ }^{\circ} \mathrm{C} ; T_{\text {д12 }}$ - температура двух фаз непропитанной обмотки в момент подключения к ней стабилизированного тока; $T_{\text {др12 }}-$ температура двух фаз непропитанной обмотки в момент времени $t_{0}$ её разогрева стабилизированным током; $\alpha$ - температурный коэффициент провода обмотки.

Вычтем $R_{\text {д12 }}$ из $R_{\text {др12 }}$ и, используя выражения (12) и (13), получим:

$$
\begin{aligned}
& R_{\text {др12 }}-R_{\text {д12 }}=R_{12 \text { 2 } 20}\left[1+\alpha\left(T_{\text {др12 }}-20\right)\right]- \\
& -R_{12 \pi 20}\left[1+\alpha\left(T_{\text {д12 }}-20\right)\right]=R_{12 \not 20} \alpha\left(T_{\text {др12 }}-T_{\text {д12 }}\right) \text {. }
\end{aligned}
$$

Из выражения (14) следует

$$
\Delta T_{\text {д12 }}=T_{\text {др12 }}-T_{\text {д12 }}=\frac{R_{\text {дp12 }}-R_{\text {д12 }}}{\alpha R_{12 \text { स2 } 2}} .
$$

Величина $R_{12 д 20}$ в общем случае неизвестна, так как начальная температура обмотки $T_{\text {д12 }}$ в момент начала измерения не равняется $20{ }^{\circ} \mathrm{C}$ и зависит от температуры окружающей среды в помещении, где производятся измерения, от технологической операции, с которой поступила обмотка на контроль и др., и может колебаться в широких пределах. Указанные колебания температуры могут привести к значительным погрешностям в определении коэффициентов пропитки. Чтобы исключить эти погрешности необходимо в момент начала контроля измерить указанную исходную температуру обмотки $T_{\text {д12. }}$. Beличину этой температуры можно узнать, измерив температуру магнитного сердечника, в который всыпана обмотка, до подачи в обмотку греющего тока. Если температура $T_{\text {д12 }}$ измерена, то величину сопротивления $R_{12220}$ двух фаз обмотки при температуpe $20{ }^{\circ} \mathrm{C}$ можно определить по первоначальному из-

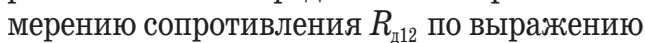

$$
R_{12 \text { др } 20}=\frac{R_{\text {д12 }}}{1+\alpha\left(T_{\text {д12 }}-20\right)} .
$$

Подставив величину $R_{12 д 20}$ из выражения (16) в формулу (15), получим:

$$
\Delta T_{\text {д12 }}=\frac{\left(R_{\text {дp } 12}-R_{\text {д12 }}\right)\left[1+\alpha\left(T_{\text {д12 }}-20\right)\right]}{\alpha R_{\text {д12 }}} .
$$

Подставив в формулу (7) $Q_{\text {д12 }}$ из выражения (11) и величину $\Delta T_{\text {д12 }}$ из выражения (17), получим значение величины $C_{\text {д12 }}$ 


$$
C_{\text {дp12 }}=\frac{\alpha t_{0} I_{0}^{2} R_{\text {д12 }}\left(R_{\text {स12 }}+R_{\text {дp12 }}\right)}{2\left(R_{\text {др12 }}-R_{\text {д12 }}\right)\left[1+\alpha\left(T_{\text {д12 }}-20\right)\right]} .
$$

Проведя аналогичные измерения у пропитанной обмотки, можно найти $C_{\text {п12 }}$ по формуле

$$
C_{\mathrm{m} 12}=\frac{\alpha t_{0} I_{0}^{2} R_{\mathrm{m} 12}\left(R_{\mathrm{m} 12}+R_{\mathrm{pm} 12}\right)}{2\left(R_{\mathrm{pm} 12}-R_{\mathrm{m} 12}\right)\left[1+\alpha\left(T_{\mathrm{m} 12}-20\right)\right]},
$$

где $R_{\text {п12 }}, R_{\text {рп12 }}$ - сопротивление двух фаз пропитанной обмотки в начальный момент времени разогрева и в момент времени $t_{0} ; T_{\text {п12 }}-$ исходная температура пропитанной обмотки в момент подключения к её двум фазам стабилизированного тока $I_{0}$.

Используя выражение (6) и подставив в него значения эквивалентных теплоемкостей двух фаз обмотки до пропитки и после неё из формул (18) и (19), получим:

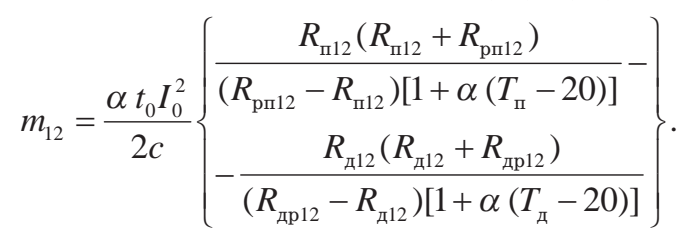

С использованием формул (2) и (3) найдем величину $m_{012}$ :

$$
m_{012}=d_{c} S_{\tilde{n}} l_{w}\left(1-\frac{\pi}{4} K_{f}\right) \cdot \frac{p}{2} .
$$

Подставив в формулу (1) значения $m_{12}$ и $m_{012}$ из выражений (20) и (21) получим:

$$
\begin{gathered}
K_{i 12}=\frac{\alpha t_{0} I_{0}^{2}}{p c d_{c} S l_{w}\left(1-p K_{f} / 4\right)} \times \\
\times\left\{\begin{array}{l}
\frac{R_{\mathrm{m} 12}\left(R_{\mathrm{m} 12}+R_{\mathrm{p} 12}\right)}{\left(R_{\mathrm{p} 12}-R_{\mathrm{m} 12}\right)\left[1+\alpha\left(T_{\mathrm{II}}-20\right)\right]}- \\
-\frac{R_{\text {д12 }}\left(R_{\mathrm{\alpha} 12}+R_{\text {дp12 }}\right)}{\left(R_{\text {дp12 }}-R_{\text {д12 }}\right)\left[1+\alpha\left(T_{\text {д }}-20\right)\right]}
\end{array}\right\} .
\end{gathered}
$$

Проведя аналогичные рассуждения, можно получить выражения для определения коэффициентов пропитки двух других пар фаз

$$
\begin{aligned}
& K_{i 13}=\frac{\alpha t_{0} I_{0}^{2}}{p c d_{c} S l_{w}\left(1-p K_{f} / 4\right)} \times \\
& \times\left\{\begin{array}{c}
\frac{R_{\mathrm{m} 13}\left(R_{\mathrm{m} 13}+R_{\mathrm{pm} 13}\right)}{\left(R_{\mathrm{p} 113}-R_{\mathrm{m} 13}\right)\left[1+\alpha\left(T_{\mathrm{m}}-20\right)\right]}- \\
-\frac{R_{\mathrm{д} 13}\left(R_{\mathrm{д} 13}+R_{\mathrm{pp} 13}\right)}{\left(R_{\mathrm{дp} 13}-R_{\mathrm{д} 13}\right)\left[1+\alpha\left(T_{\text {д }}-20\right)\right]}
\end{array}\right\} . \\
& K_{i 23}=\frac{\alpha t_{0} I_{0}^{2}}{p c d_{c} S l_{w}\left(1-p K_{f} / 4\right)} \times
\end{aligned}
$$

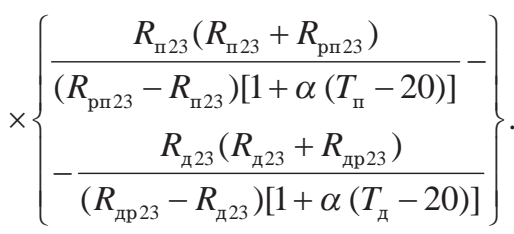

Коэффициенты пропитки $K_{i 12}, K_{i 13}, K_{i 22}$, определенные по выражениям (22)-(24), являются среднестатистической характеристикой пропитки соответствующих двух фаз $i$-й обмотки, и их величины можно определить из выражений:

$$
\begin{gathered}
K_{i 12}=\frac{K_{i 1}+K_{i 2}}{2}, \\
K_{i 13}=\frac{K_{i 1}+K_{i 3}}{2}, \\
K_{i 23}=\frac{K_{i 3}+K_{i 2}}{2},
\end{gathered}
$$

где $K_{i 1}, K_{i 2}, K_{i 3}-$ коэффициенты пропитки фаз 1,2 и 3. Решив систему уравнений (25)-(27) относительно коэффициентов пропитки фаз $K_{i 1}, K_{i 2}, K_{i 3}$, получим:

$$
\begin{aligned}
& K_{i 1}=K_{i 12}-K_{i 23}+K_{i 13}, \\
& K_{i 2}=K_{i 23}-K_{i 13}+K_{i 12}, \\
& K_{i 3}=K_{i 13}-K_{i 12}+K_{i 23} .
\end{aligned}
$$

Используя выражения (28)-(30) можно определить насколько равномерно или не равномерно пропиточный состав распределился в процессе операций пропитки и сушки по фазам обмотки.

\section{Практическая реализация предлагаемого способа}

Структурная схема устройства, реализующего рассмотренный электротепловой способ, приведена на рис. 1.

Устройство содержит: собственно прибор КПР$1 \mathrm{~A}$, вычислительный блок (ВБ) и контактор. ВБ содержит микрокалькулятор (МК) со встроенным узлом сопряжения (УС) с прибором.

Прибор КПР-1А содержит следующие субблоки: стабилизатор тока (СТ), синхронизатор (С), схему защиты (С3), схему термостатирования и компенсации (СК), блок настройки компенсатора (БНК), аналого-цифровой преобразователь (АЦП1), индикатор напряжения (ИН) и блоки питания (БП).

Прибор работает следующим образом. Заземленная обмотка статора подключается к прибору в качестве выходной нагрузки СТ, который преобразует выпрямленное напряжение отрицательной полярности в стабилизированный ток $I_{0}$, величина которого задается опорным напряжением с БНК в соответствии с типом контролируемого двигателя. Напряжение обмотки $U_{\text {обм }}$ контролируемого статора поступает в СК, в состав которой входит узел термокомпенсации и вычитания. Схема термокомпенсации посредством датчика температуры (Д) преобразует температуру статора $T_{\mathrm{c}}$ в положительное или отрицательное напряжение термокомпенсации $U_{\text {тк }}$, которое пропорционально по величине отклонению температуры статора от температуры $20{ }^{\circ} \mathrm{C}$ и имеет знак «+», если температура статора больше $20{ }^{\circ} \mathrm{C}$, и знак «-», если наоборот.

$$
U_{\text {тк }}=I_{0} R_{\mathrm{H}} \alpha\left(T_{\mathrm{c}}-20\right),
$$

где $R_{\text {н }}$ - номинальное сопротивление обмотки при $20{ }^{\circ} \mathrm{C}$. 


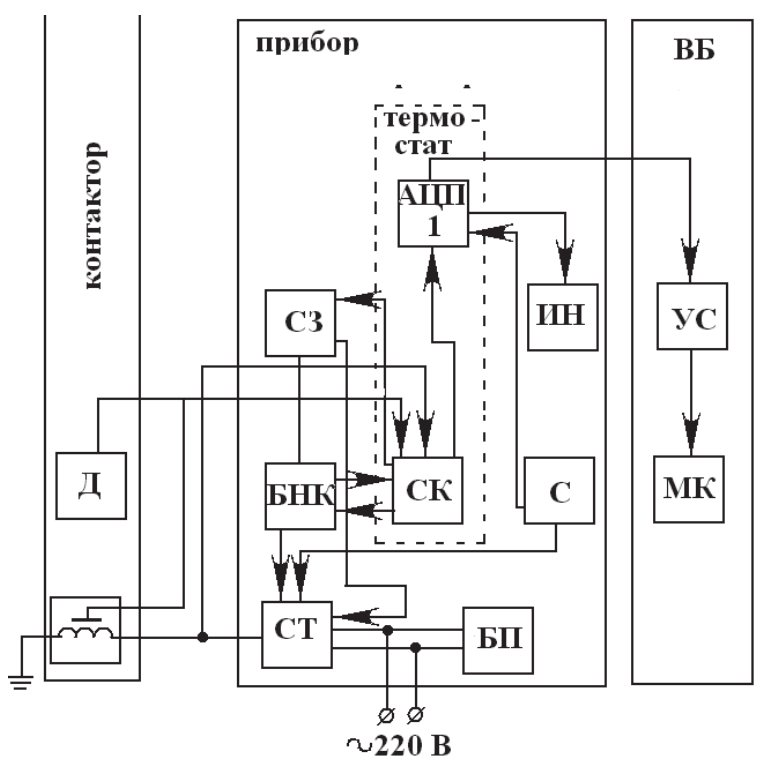

Puс.1. Структурная схема прибора контроля пропитки

Fig. 1. Block diagram of impregnation control device

Схема вычитания в зависимости от типа двигателя формирует напряжение вычитания, знак которого противоположен знаку $U_{\text {обм }}$, величина равна

$$
U_{\mathrm{B}}=I_{0} \alpha\left(R_{\mathrm{H}}-\Delta R\right),
$$

где $\Delta R$ - допустимое отклонение сопротивления обмотки в сторону уменьшения при $20^{\circ} \mathrm{C}$.

Вычитание постоянной составляющей осуществляется для обеспечения более точного измерения изменения напряжения в процессе нагрева. Схема компенсации включается с задержкой $t=0,25$ с и осуществляет суммирование напряжений обмотки, вычитания и термокомпенсации. Задержка суммирования предусмотрена с целью защиты входа сумматора от переходных процессов напряжения обмотки в момент включения стабилизатора тока.

$$
U_{\mathrm{K}}=U_{\text {об̆ }}+U_{\mathrm{B}}+U_{\text {тк }}
$$

где величины $U_{\text {в }}$ и $U_{\text {тк }}$ находятся по выражениям (31) и (32).

Результат суммирования поступает в АЦП1 и схему защиты, где его значение сравнивается с пороговыми значениями. При несоответствии сопротивления обмотки допустимым пределам С3 отключает СТ и сигнализирует лампами «КЗ» или «Обрыв». Скомпенсированное напряжение $U_{\mathrm{K}}$ измеряется АЦП1 дважды: в момент времени $t=0,5$ с и $t=t_{\text {опт }}$, устанавливаемого переключателем «время опт». Результат измерения в параллельном двоично-десятичном коде поступает на индикатор напряжения ИН и с помощью соединительного кабеля в узел сопряжения ВБ на МК. Блок сопряжения преобразует его в последовательный десятичный код, вводит в микрокалькулятор МК и осуществляет старт программы ВБ, которая рассчитывает теплоемкость обмотки $C_{\text {экв }}$ по формуле

$$
C_{\text {эКв }}=\frac{I_{0} t_{0}\left[\left(U_{\mathrm{B}}+U_{\mathrm{K} 1}\right)\left(U_{\mathrm{B}}+U_{\mathrm{K} 2}\right)\right]\left(U_{\mathrm{B}}+U_{\mathrm{K} 1}\right) \alpha}{2\left(U_{\mathrm{K} 2}-U_{\mathrm{K} 1}\right)} .
$$

где $U_{\text {к1 }}, U_{\text {к1 }}$ - значения скомпенсированных напряжений в момент времени $t=0,5$ с и $t=t_{\text {опт }}$ соответственно. Эти величины рассчитываются по формуле (33).

\section{Анализ погрешностей контроля}

Результирующая погрешность электротеплового способа и прибора контроля коэффициента пропитки складывается из методических и инструментальных ошибок.

Абсолютная методическая погрешность обусловлена ошибкой определения эквивалентной теплоемкости обмотки по формулам (7), (18) и (19) и равна

$$
\Delta C=C_{\mathrm{T}}-C_{\text {ист }},
$$

где $C_{\text {ист }}$ - истинное значение эквивалентной теплоемкости обмотки, определяемое выражением (7), (18) или (19) для идеализированной обмотки; $C_{\text {т }}-$ экспериментальное значение теплоёмкости реальной обмотки, определяемое по выражению (34).

Методическая погрешность обусловлена неидеальностью обмотки и зависит от выбора времени измерения параметров обмотки при её контроле $t=t_{\text {опг }}$. Эта ошибка рассчитывается численным методом с использованием электротепловой аналогии по электротепловым схемам идеализированной и реальной обмотки, подробно изложенным в работе [26]. При построении графиков использовались обмоточные данные статоров электродвигателя 4AM80 при разогреве этой обмотки стабилизированным током $I_{0}=12,4$ A.

Величину постоянного стабилизированного тока выбирали исходя из допустимых плотностей тока $j$ для медного провода, лежащих в диапазоне от 6 до 10 A $/$ мм² $^{2}[32,33]$, и площади сечения провода.

При этом плотность тока $6 \mathrm{~A} /$ мм $^{2}$ считается нормальной плотностью, взятой с запасом, а плотность тока $10 \mathrm{~A} / \mathrm{Mм}^{2}$ - это максимально допустимая плотность, которая пригодна только для кратковременной эксплуатации. В нашем случае при кратковременном воздействии постоянного стабилизированного тока $I_{0}$ на объект контроля (обмотку) целесообразно выбирать плотность тока, близкую к максимально допустимой, равной $10 \mathrm{~A} / \mathrm{Mм}^{2}$. Это обусловлено тем, что, во-первых, воздействие тока на провод обмотки в процессе контроля пропитки кратковременно, и, во-вторых, тем, что чем выше плотность тока, тем быстрее происходит изменение температуры провода, что сокращает время контроля. Поэтому для разрабатываемого способа контроля качества пропитки обмоток электротехнических изделий следует обузить интервал плотностей тока до значений от 8 до 10A/ мм $^{2}$. Указанный выбранный интервал тока для контроля пропитки обмоток электротехнических изделий, изготовленных из медного провода, обусловлен следующими причинами. Плотность тока для медных проводов более $10 \mathrm{~A} / \mathrm{mm}^{2}$ недопустима. Значение плотностей тока меньше $8 \mathrm{~A} / \mathrm{Mм}^{2}$ приводит к увеличению времени контроля и точности измерений коэффициентов пропитки. В данном конкрет- 
ном случае площадь сечения медного провода контролируемой обмотки была равной 1,368 мм² $^{2}$ Исходя из выбранного диапазона допустимых плотностей тока от 8 до $10 \mathrm{~A} / \mathrm{Mm}^{2}$, значение постоянного стабилизированного тока $I_{0}$ должно лежать в диапазоне от 10,9 до 13,67 А. Нами был выбран ток, лежащий примерно в середине указанного диапазона и равный $12,4 \mathrm{~A}$.

Инструментальная (аппаратурная) погрешность - это погрешность, принадлежащая средству измерения. Поскольку контроль теплоёмкости осуществляется косвенным путём по результатам измерений скомпенсированных напряжений $U_{\text {к1 }}$ и $U_{\text {к2}}$, то задача расчета аппаратурной погрешности сводится к суммированию погрешностей измерения $U_{\text {к1 }}$ и $U_{\text {к2 }}$ с учетом их вклада в результирующую погрешность в зависимости от выражения (34).

$$
\Delta C_{\mathrm{a}}=C_{\text {ид }}\left(B_{1} \frac{\Delta U_{\mathrm{\kappa} 1}}{U_{\mathrm{\kappa} 1}}+B_{2} \frac{\Delta U_{\mathrm{\kappa} 2}}{U_{\mathrm{\kappa} 2}}\right),
$$

где $C_{\text {дд }}$ - истинная теплоёмкость обмотки.

Для определения чувствительности $\Delta C_{\text {а }}$ к изменению погрешностей $\frac{\Delta U_{\text {к1 }}}{U_{\text {к1 }}}, \frac{\Delta U_{\text {к2 }}}{U_{\text {к2 }}}$ используем общий прием [34], заключающийся в определении частных производных по выражению (34)

$$
\begin{aligned}
& B_{1}=
\end{aligned}
$$

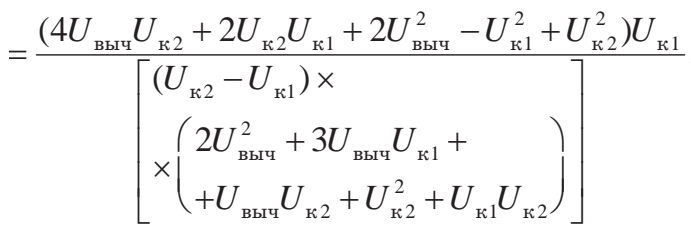

$$
\begin{aligned}
& B_{2}=\frac{2\left(U_{\mathrm{Bыч}}+U_{\mathrm{k} 1}\right) U_{\mathrm{\kappa} 2}}{\left(U_{\mathrm{\kappa} 2}-U_{\mathrm{k} 1}\right)\left(2 U_{\text {выч }}+U_{\mathrm{k} 1}+U_{\mathrm{k} 2}\right)} .
\end{aligned}
$$

Так как в процессе нагрева обмотки её сопротивление увеличивается, скомпенсированное напряжение обмотки в режиме стабилизированного тока для моментов времени $t=0,5$ с и $t=t_{\text {опт }}$ будет определяться выражениями:

$$
\begin{gathered}
\Delta U_{\mathrm{k} 1}=I \Delta R, \\
\Delta U_{\mathrm{K} 2}=I R_{\mathrm{H}}\{1+\alpha[T(t-20)]\} .
\end{gathered}
$$

Следовательно, коэффициенты $B_{1}$ и $B_{2}$, входящие в выражение (36), в соответствии с величинами, определяемыми по формулам (37)-(40), зависят от времени контроля. Для определения факторов, связанных с погрешностями $\Delta U_{\text {к1 }}$ и $\Delta U_{\text {к2 }}$, проведём анализ структурной схемы прибора (рис. 1).

Погрешности подразделяются по окружающим условиям на основные и дополнительные, а по условиям их появления - на статические и динамические [34]. К числу основных статических погрешностей относятся несоответствия используемых по формуле (34) значений констант, которые определяются только типом контролируемого двигателя, и их действительных значений, зависящих от точности настройки: напряжения вычитания
$\Delta U_{\text {выч}}$, оптимального времени контроля $\Delta t_{\text {опт }}$ и напряжения термокомпенсации $\Delta U_{\text {тк }}$. Поскольку ток, напряжение вычитания и напряжение термокомпенсации задаются опорным напряжением, выставленным с помощью делителей, точность их настройки определяется разрешающей способностью подстроечных резисторов. Использовав многооборотные резисторы типа СП5-3 с разрешающей способностью 9,3 \% (по справочным данным) от номинального значения, мы добились следующей точности для контроля электродвигателя 4AM80A4: $\Delta I_{0}=1,24 \cdot 10^{-4} \mathrm{~A} ; \quad \Delta U_{\text {выч }}=-2,8 \cdot 10^{-3} \mathrm{~B}$; $\Delta U_{\mathrm{K}}=4,1 \cdot 10^{-4} \mathrm{~B}$.

Точность отсчета оптимального времени контроля $t_{\text {опт }}$ с момента запуска прибора на измерение связана с нестабильностью тактовых импульсов, которые поступают с генератора, собранного на кварцевом резонаторе РВ-72 с частотой резонирования (3276810) Гц. Такая подстройка частоты осуществлялась переменным воздушным конденсатором. Количественная оценка погрешности генератора показала, что отклонение $\Delta t_{\text {опт }}$ настолько мало, что им, с учетом дальнейшего влияния на измеряемую величину, можно пренебречь. Указанные неточности настройки отдельных параметров прибора приводят к систематической погрешности в измерении скомпенсированного напряжения, определяемого выражением (34), согласно которому суммарная погрешность равна

$$
\Delta U_{\mathrm{K}}=I_{0} R_{\mathrm{H}}+\Delta U_{\text {выч }}+\Delta U_{\text {тк }} .
$$

Основная динамическая погрешность прибора связана с запаздыванием процесса измерения скомпенсированного напряжения, поскольку используется АЦП последовательного типа.

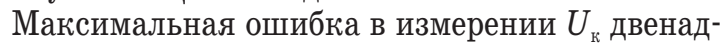
цатиразрядным АЦП составит

$$
\Delta K_{\text {кд }}=2^{12} \frac{K_{\text {й }}}{f},
$$

где $K_{\text {и }}$ - крутизна нарастания скомпенсированного напряжения по времени; $f=20$ кГц - частота тактового генератора АЦП. Количественная оценка динамической погрешности $\Delta U_{\text {кд }}$ по формуле (42) показывает, что она пренебрежительно мала.

Дополнительные погрешности возникают при отклонении условий работы прибора от номинальных. Поскольку прибор эксплуатируется в лабораторных или заводских условиях в стационарном положении, дополнительные погрешности определяются в основном климатическими условиями, параметрами внешних полей и параметрами режимов питания. Для устранения первых двух причин основные узлы прибора (ИОН, СК, АЦП) размещены в экранированный, термостатированный корпус.

Погрешность, связанная с нестабильностью источников питания, является мультипликативной и распределена по тому же закону, что и отклонения напряжения в сети. В данном случае основная погрешность вносится источником опорного напряжения, а погрешности, связанные с отклонениями 
коэффициентов усиления напряжений смещения, незначительны. Например, колебания в сети в пределах $\pm 16 \%$, с учетом коэффициентов стабилизации стабилизатора напряжения $K_{\text {сссн }}=0,5 \%$ и ИОН $K_{\text {стоп }}=0,02 \%$, влекут за собой отклонение опорного напряжения на величину $\Delta U_{\text {оп }}=1,24 \cdot 10^{-3} \mathrm{~B}$. Изменение $U_{\text {оп }}$ приводит к погрешности упомянутых параметров $I_{0}, U_{\text {в }}, U_{\text {тк }}: \Delta I_{0 д}=4,78 \cdot 10^{-4} \mathrm{~A} ; \Delta U_{\text {вычд }}=6,8 \cdot 10^{-4} \mathrm{~B}$; $\Delta U_{\text {ткд }}=1,3 \cdot 10^{-3} \mathrm{~B}$. Поскольку перечисленные выше погрешности вызваны одной причиной, т. е. коррелированы между собой, суммирование их осуществляется также, как и в формуле (41), с учётом знака составляющей [34].

$$
\Delta U_{\text {тд }}=\Delta I_{0 \text { д }} \cdot R_{\text {н }}-\Delta U_{\text {выхд }}+\Delta U_{\text {ткд }} \cdot
$$

Таким образом, абсолютная погрешность измерения скомпенсированного напряжения будет складываться из основной и дополнительной погрешностей по их абсолютным величинам

$$
\Delta U_{\mathrm{K}}=\Delta U_{\mathrm{k0}}+\Delta U_{\mathrm{kम}} \text {. }
$$

Результирующая погрешность определения теплоемкости обмотки является суммой методической и инструментальной погрешностей. При суммировании погрешностей следует учитывать два момента: методическая и аппаратурная погрешности имеют зависимости от времени и мощности разогрева обмотки в процессе контроля; методическая погрешность является систематической погрешностью, а аппаратурная - случайной.

Исходя из вышесказанного, результирующая погрешность в определении теплоёмкости непропитанной обмотки $\Delta C_{\text {тд }}$

а пропитанной $\Delta C_{\text {тд }}$

$$
\Delta C_{\text {тд }}=\Delta C_{\text {тдм }} \pm \Delta C_{\text {тда }},
$$

$$
\Delta C_{\text {тा }}=\Delta C_{\text {тाм }} \pm \Delta C_{\text {тाа }} .
$$

Входящие в правые стороны формул (45) и (46) величины определяются по формулам (35) и (36).

Погрешность определения массы состава в контролируемой обмотке $\Delta m_{\text {c }}$ рассчитывается согласно выражению (6) по формуле

$$
\Delta m_{\mathrm{c}}=\frac{\Delta \tilde{N}_{\mathrm{TI}}-\Delta \tilde{N}_{\mathrm{TH}}}{\tilde{n}_{\mathrm{c}}} .
$$

Однако необходимо учесть, что погрешности $\Delta C_{\text {тд }}$ и $\Delta C_{\text {тI }}$ находятся в некоторой полосе неопределенностей, границы которой описаны выражениями (43) и (44).

Для расчета методической и аппаратурной погрешностей с использованием электротепловых схем замещения была составлена программа, основанная на анализе переходных тепловых процессов в идеализированных и реальных обмотках. Эта программа позволяла производить анализ методической, аппаратурной и результирующей погрешностей, осуществлять определение величин (43),

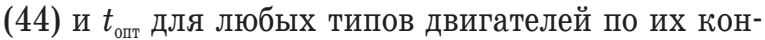
структивным и обмоточным данным. Абсолютная погрешность в измерении эквивалентной теплоёмкости реальной обмотки, как до пропитки $\Delta C_{\text {тда, }}$, так и после неё $\Delta C_{\text {тп }}$ определяется классом точности измерителя температуры и вычисляется по формулам

$$
\begin{gathered}
\Delta C_{\text {тда }}= \pm\left[A+B \frac{T_{\text {пр }}}{T_{\text {дпі }}(t)}\right], \\
\Delta C_{\text {тда }}= \pm\left[A+B \frac{T_{\text {пр }}}{T_{\text {ппі }}(t)}\right],
\end{gathered}
$$

где $A$ и $B$ - константы, определяемые классом точности измерителя температуры; $\mathrm{T}_{\text {пр }}$ - предельное значение шкалы измерителя температуры; $T_{\text {дпі }}$ и $T_{\text {ппі }}$ - изменение температуры непропитанной и пропитанной обмотки в процессе их разогрева при контроле. Для определения аппаратурной погрешности по выражениям (47) и (48) нужно задаться величинами $A, B$ и $T_{\text {пр }}$. Предварительный анализ показал, что для обеспечения необходимой точности измерения величины $T_{\text {дпі }}$ и $T_{\text {ппі }}$ следует использовать измеритель сопротивления с пределом $R_{\text {пр }} \cong 0,1$ Ом. В пересчете на температуру предельная шкала измерителя составит

$$
T_{\text {пр }}=\frac{R_{\text {пр }}}{2 R_{\text {क }} \alpha_{R}},
$$

где $R_{\phi}$ - номинальное сопротивление двух фаз обмотки; a? ${ }_{R}$ - температурный коэффициент сопротивления провода обмотки.

Для измерения приращения температуры в контролируемых обмотках был выбран цифровой вольтметр В-7-27. Он обеспечивает измерение сопротивления по постоянному току в диапазоне от 0,001 Ом до 20 МОм. По паспортным данным этого вольтметра $A=0,002, B=0,002$.

Зависимость результирующей погрешности определения эквивалентной теплоемкости, пропитанной (2) и непропитанной (1) теплоемкостей обмоток от времени их разогрева при контроле демонстрируют графики, приведенные на рис. 2.

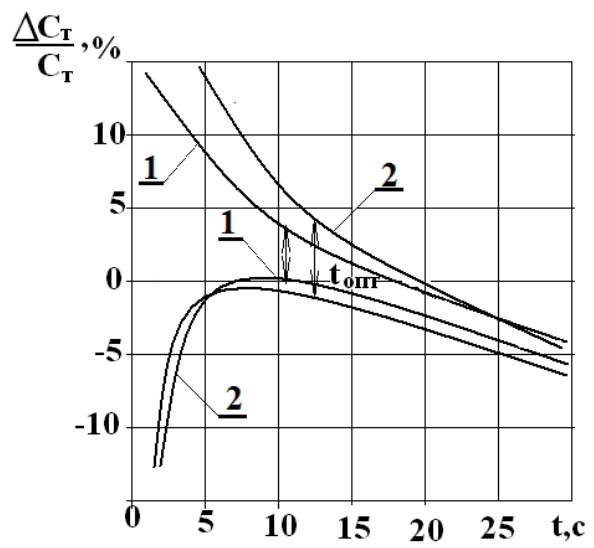

Рис. 2. Зависилость результирующей погрешности определения эквивалентной теплоелкости от времени излерения температуры обмотки

Fig. 2. Dependence of the resulting error of determining the equivalent heat capacity on the time of winding temperature measurement

Эти погрешности, так же как и аппаратурные погрешности, находятся в некоторой полосе нео- 
пределенностей. Очевидно, что оптимальным является такое время контроля, при котором результирующая погрешность минимальна по абсолютной величине независимо от знака погрешности. Таким временем $t_{\text {опт }}$ является время, от которого границы результирующей погрешности равноудалены. $\mathrm{Pe}$ зультаты расчета относительной результирующей

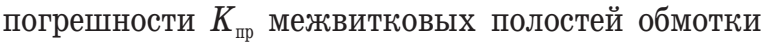
двигателя 4AM80A4 при $t_{\text {опт }}=19$ с показали, что относительная погрешность не превышает 2,2 \% .

Сравнение возможностей разработанного способа и прибора с методом контроля по привесу, предложенным Форкманном [35], осуществлялось по следующей методике.

В обмотки двух статоров электродвигателя вливалась строго дозированная, измеренная с помощью аналитических весов масса пропиточного состава, соответствующая коэффициентам пропитки $K_{\text {пр1 }}=0,03$ и $K_{\text {пр2 }}=0,6$. Относительная погрешность измерения при помощи прибора была равна, соответственно

$$
\frac{\Delta K_{\text {пр1 }}}{K_{\text {пр1 }}} 100 \%=1,6 \%, \frac{\Delta K_{\text {пр } 2}}{K_{\text {пр2 }}} 100 \%=0,9 \% .
$$

Так как погрешность измерения коэффициента пропитки складывается из аддитивных и мультипликативных ошибок, то в соответствии с [34] для приведенной погрешности $K_{\text {пр2 }}=0,6$ можно записать

$$
\begin{gathered}
\gamma_{s}+\gamma_{\text {н }}+\gamma_{\text {к }}=\frac{\Delta K_{\text {пр } 2}}{K_{\text {пр2 }}}, \\
\gamma_{s}+\gamma_{\text {н }} \frac{0,06}{0,03}=\frac{\Delta K_{\text {пр } 2}}{K_{\text {пр2 }}},
\end{gathered}
$$

где $\gamma_{\text {н }} \frac{\Delta_{0}}{\tilde{O}_{\text {к }}}\left(X_{\kappa}=K_{\text {пр } 2}\right)$ - приведенное значение погрешности в начале диапазона; $\Delta_{0}$ - аддитивная погрешность; $\gamma_{s}$ - мультипликативная погрешность. Из уравнений (48), (49) следует, что $\gamma_{s}=0,86$; $\gamma_{\mathrm{H}}=0,037$, т. е. класс прибора в соответствии с ГОСТ8.401-80 можно оценить как $(0,9 / 0,04)$.

\section{СПИСОК ЛИТЕРАТУРЫ}

1. Курбатова 0.А., Павлюченко В.М. Монтаж и ремонт горных машин и электрооборудования. - Владивосток: Изд-во ДВГТУ, 2004. -286 c.

2. Колмаков Е.А., Кондрашов П.М., Зеньков И.В. Обзор конструкций фильтров в составе погружных электроцентробежных насосов при добыче нефти // Вестник КузГТУ. - 2016. № 1. - C. $150-155$.

3. Компьютерная система для функциональной диагностики электроприводов карьерных экскаваторов // В.Г. Каширских, А.Н. Гаргаев, В.М. Завьялов, И.Ю. Семыкина // Вестник КузГТУ. - 2016. - № 6. - С. 159-168.

4. Русский Е.Ю. Анализ прочности роторов шахтных осевых вентиляторов // Вестник КузГТУ. - 2015. - № 2. - С. 31-34.

5. Герике П.Б. Определение дефектов динамического оборудования тяговых лебедок экскаваторов типа драглайн по параме-
Если взять весы того же класса точности, то погрешность определения ими массы пропиточного состава $m_{\mathrm{c}}=60$ г в обмотке при массе статора с обмоткой электродвигателя 4AM80A4, равной $m_{\mathrm{cr}}=6$ кг, при взвешивании его на весах с предельной шкалой $m_{\mathrm{K}}=10 \mathrm{\kappa г,} \mathrm{дает} \mathrm{абсолютную} \mathrm{погреш-}$ ность, равную

$$
\begin{gathered}
\Delta m_{\text {ст }}=\left(\frac{\gamma_{\text {н }}}{100} m_{\mathrm{r}}+\frac{\gamma_{s}}{100} m_{\text {ст }}\right)= \\
= \pm\left(\frac{0,04 \cdot 10^{4}}{100}+\frac{0,86 \cdot 10^{3}}{100}\right)=55,6 \text { ã. }
\end{gathered}
$$

Относительная погрешность определения массы пропиточного состава $m_{\mathrm{c}}=60$ г весовым методом составит

$$
\frac{\Delta m_{\text {ст }}}{m_{\text {с }}} \cdot 100 \%= \pm \frac{55,6}{60} \cdot 100 \%= \pm 92,7 \% .
$$

Таким образом, за счет исключения мощной помехи, которой является масса магнитного сердечника, в электротепловом способе контроля, путем создания в обмотке адиабатического процесса, точность определения коэффициента пропитки увеличена в сравнении с методом контроля по привесу [35] при одинаковом классе точности измерителей в 57 раз. Дополнительным преимуществом разработанного способа, по сравнению с методом контроля по привесу, является то, что он позволяет определить, как пропиточный состав распределился по фазам обмотки, чего невозможно сделать методом контроля по привесу.

\section{Заключение}

В результате проведенной работы был рассмотрен электротепловой способ контроля качества пропитки обмоток. Приведена структурная схема прибора, в котором реализован созданный метод контроля. Проведен анализ методических и аппаратурных погрешностей разработанного способа и прибора контроля. Показано, что результирующая погрешность контроля находится в диапазоне $(1,62,2) \%$.

трам механических колебаний // Вестник КузГТУ. - 2014. № 1. - С. 21-26.

6. Смирнов Г.В. Ресурсосберегающая технология пропитки обмоток электротехнических и радиотехнических изделий // Электрооборудование: эксплуатация и ремонт. - 2018. № 4. - C. 31-45.

7. A new generation of aluminum enameled winding wires / T. Knych, A. Mamala, P. Uliasz, M. Jabloński // Wire Journal International. - 2012. - V. 45. - № 1. - P. 55-61.

8. Gupta B. Risk in surge testing of turn insulation in windings of rotating machines // Electrical Insulation Conference and Electrical Manufacturing \& Coil Winding Technology Conference. Chicago, June 2003. - P. 459-462.

9. A new generation of aluminum enameled winding wires / B. Smyrak, T. Knych, A. Mamala, P. Uliasz, M. Jabloński // Wire Journal International. - 2012. - V. 45. - № 1. - P. 55-61. 
10. PDIV characteristics of twisted-pair of magnet wires with repetitive impulse voltage / K. Kimura, S. Ushirone, T. Koyanagi, M. Hikita / IEEE Trans. on Dielectrics and Electrical Ins. - Chicago, June 2007. - V. 14. - № 3. - P. 744-750.

11. Chapman M., Frost N., Bruetsch R. Insulation systems for rotating low-voltage machines // IEEE International Symposium on Electrical Insulation. Chicago, June 2008. - P. 257-260.

12. Accessing the insulation characteristics for stator windings of low-voltage induction motors for adjustable-speed drive applications / D. Hwang, K. Lee, Y. Kim, I. Lee, T. Lim, D. Kim // IEEE Industry Application Conference. Chicago, June 2003. - V. l. P. $432-438$

13. Electrical aging of the insulation of low voltage machines: model definition and test with the design of experiments / N. Lahoud, J. Faucher, D. Malec, P. Maussion / IEEE Transactions on Industrial Electronics. - 2013. - V. 60. - № 5. - P. 60-67.

14. Leonov A.P., Redko V.V., Soldatenko E.Yu. Estimation of winding insulation resistance to the corona discharges // IOP Conference Series: Materials Science and Engineering. - 2014. V. 66. - P. 1-5.

15. PDIV characteristics of twisted-pair of magnet wires with repetitive impulse voltage / K. Kimura, S. Ushirone, T. Koyanagi, M. Hikita // IEEE Trans. on Dielectrics and Electrical Ins. - Chicago, June 2007. - V. 14. - № 3. - P. 744-750.

16. ГОСТ IEC 60851-5-2011. Провода обмоточные. Методы испытаний. Ч. 5. Электрические свойства. - М.: Стандартинформ, 2014. -19 c.

17. Bellomo J.P., Castelan P., Lebey T. The effect of pulsed voltages on dielectric material properties // IEEE Transactions on Dielectrics and Electrical Insulation. - 1999. - V. 6. - № 2. - P. 20-26.

18. Борисенко А.И., Костиков 0.Н., Яковлев А.И. Охлаждение промышленных электрических машин. - М.: Энергоатомиздат, 1983. - 296 с.

19. Смирнов Г.В. Магнитодиэлектрический состав, его свойства и применение в ресурсосберегающей технологии пропитки обмоток электротехнических изделий / Электрооборудование: эксплуатация и ремонт. - 2018. - № 12. - С. 55-69.

20. A new generation of aluminum enameled winding wires / B. Smyrak, T. Knych, A. Mamala, P. Uliasz, M. Jabloński // Wire Journal International. - 2012. - V. 45. - № 1. - P. 55-61.

21. Prasad A., Prasad K. Effective permittivity of random composite media: a comparative study // Physica. - 2007. - V. 396. P. 132-137.

22. Похолков Ю.П., Бесперстов П.П., Пыхтин В.В. Исследование влияния технологического процесса изготовления обмоток на дефектность витковой изоляции асинхронных двигателей // Известия Томского политехнического института. - 1975. T. $222 .-$ C. $52-65$.
23. Кондратьева Н.Г., Кузнецов Н.А. Сравнительная оценка коэффициентов заполнения паза пропиточным составом, определенных различными методами // Технология электротехнического производства. - 1981. - № 12. - С. 14-16.

24. Дудкин А.Н. Разработка методов оценки технологического процесса пропитки обмоток асинхронных двигателей: дис. ... канд. техн. наук. - Томск, 1980. - $163 \mathrm{c.}$

25. Смирнов Г.В., Смирнов Д.Г. Ёмкостной контроль качества пропитки обмоток электрических машин общепромышленного применения. // Электрооборудование: эксплуатация и ремонт. - 2018. - № 3. - С. 68-77.

26. Смирнов Г.В. Надежность изоляции обмоток электротехнических изделий. - Томск: Изд-во Томского государственного университета, 1990. - 192 с.

27. Frost N., Chapman M., Bruetsch R. Considerations for rotating low-voltage machine insulation designs // IEEE Insulation. 2008. - P. 571-574.

28. A survey on testing and monitoring methods for stator insulation systems of low-voltage induction machines focusing on turn insulation problems / S. Grubic, J.M. Aller, B. Lu, T.G. Habetler // IEEE Transactions on Industrial Electronics. - 2008. - V. 55. № 12. - P. 4127-4134.

29. Halpem E.H. Interaction of varnish with magnet wire enamel // IEEE Transactions on Electrical Insulation. - 1967. - V. 2. № 3. - P. 141-145.

30. Хомутов С.0., Кобозев Е.В., Семичевский П.И. Повышение эффективности восстановления изоляции электрических двигателей на основе комплексной оценки воздействующих факторов // Ползуновский вестник. - 2009. - № 1, 2. - С. 220-229.

31. Смирнов Г.В. Контроль качества проведения операций пропитки и сушки обмоток электродвигателей // Электрооборудование: эксплуатация и ремонт. - 2018. - № 5. - С. 24-36.

32. Смирнов Г.В. Пооперационный контроль процесса изготовления обмоток электрических машин. - М.: Научно-техническое издательство «Горячая линия - Телеком», 2018. - 156 с.

33. Смирнов Г.В., Смирнов Д.Г. Способ определения коэффициента пропитки отверждаемым полимерным составом обмоток электрических машин: пат. РФ № 2521439; заявл. 25.10.2012; опубл. 27.06.2014, Бюл. № 18. -22 с.

34. Новицкий П.В., Зограф И.А. Оценка погрешностей результатов измерений. - Л.: Энергоатомиздат, Ленингр. Отд-ние, 1985. -248 c.

35. Forkmann H. Die rcsulticrcnde warmeleitfahig keit getranker Wicklungcn aus Runddraht niit Lackisolation // Deutsche Electrolechnik. - 1957. - H. 12. - Bd. 11. - P. 533-536.

Поступила 30.12.2018 г.

\section{Информация об авторах}

Слирнов Г.В., доктор технических наук, профессор, директор Научно-исследовательского института электронного технологического оборудования и систем связи Томского государственного университета систем управления и радиоэлектроники.

Ведяшкин M.B., кандидат технических наук, доцент отделения контроля и диагностики Инженерной школы неразрушающего контроля Национального исследовательского Томского политехнического университета. 


\title{
CONTROL OF IMPREGNATION IS AN EFFECTIVE FACTOR IN INCREASING THE RELIABILITY OF MOTORS IN THE MINING, CONSTRUCTION AND OTHER INDUSTRIES
}

\author{
Gennady V. Smirnov', \\ smirnov@main.tusur.ru \\ Maxim V. Vedyashkin², \\ vedyashkin@tpu.ru \\ 1 Tomsk State University of Control Systems and Radioelectronics, \\ 40, Lenin avenue, Tomsk, 634050, Russia. \\ 2 National Research Tomsk Polytechnic University, \\ 30, Lenin avenue, Tomsk, 634050, Russia.
}

Failure of the electric machine leads to emergencies, equipment downtime and, as a consequence, high economic costs to eliminate the results of machine failure. The failure of electrical machines at investigation, production and transportation of georesources in oil-extracting, mining, coal, chemical and other industries damages most of all the domestic economy. Reliability of these machines is determined by technological operations of impregnation and drying of windings. The most important qualitative characteristics of the windings are formed on these operations: electroinsulating, thermal, moisture resistant and mechanical. These properties depend on the degree of cavities filling of the winding with the impregnating composition. Low-quality impregnation of windings leads to the defects in the inter-coil insulation during storage and transportation of equipment to the place of operation. The development of quality control methods of windings impregnation is an actual problem.

The aim of the work is to show the possibility of controlling the distribution of the impregnating composition on the winding by measuring the heat capacity of the windings before and after impregnation.

Research methods: electrothermal and electromagnetic research methods, which are related to the measurement of thermal parameters of the winding and individual electrical quantities.

Results. The paper considers the electrothermal method of quality control of windings impregnation. Physical bases of quality control of impregnation are proved. The paper introduces the derivation of the main criterions of quality assessment for technological operations and the scheme of the control device. The authors considered the principle of its operation and analyzed the errors for the offered method of control.

Key words:

Winding, impregnating composition, control system, converter, heat capacity, resistance, time, generator, trigger, counter.

\section{REFERENCES}

1. Kurbatov 0.A., Pavlyuchenko V.M. Montazh i remont gornykh mashin i elektrooborudovaniya [Installation and repairing of mining machinery and electrical equipment]. Vladivostok, DVGTU Publ. house, 2004. 286 p.

2. Kolmakov E.A., Kondrashov P.M., Zenkov I.V. Review of filter design in the composition of electrical submersible pumps in oil production. Bulletin of KuzGTU, 2016, no. 1, pp. 150-155. In Rus.

3. Kashira V.G., Garaev A.N., Zavyalov V.M., Semykina I.Yu. Computer system for functional diagnostics of electric drives of quarrytion excavators. Bulletin of KuzGTU, 2016, no. 6, pp. 159-168. In Rus.

4. Russian E.Y. The analysis of the strength of the rotor shaft of axial fans. Bulletin of KuzGTU, 2015, no. 2, pp. 31-34. In Rus.

5. Gerik P.B. Defining defects of dynamic equipment, traction hoists excavators of the dragline type in the parameters of mechanical vibrations. Bulletin of KuzGTU, 2014, no. 1, pp. 21-26. In Rus.

6. Smirnov G.V. Resource-saving technology of impregnation of windings of electrotechnical and radio engineering products. Electrical Equipment: operation and repair, 2018, no. 4, pp. 31-45. In Rus.

7. Knych T., Mamala A., Uliasz P., Jabloński M. A new generation of aluminum enameled winding wires. Wire Journal International, 2012, vol. 45, no. 1, pp. 55-61.

8. Gupta B. Risk in surge testing of turn insulation in windings of rotating machines. Electrical Insulation Conference and Electri- cal Manufacturing \& Coil Winding Technology Conference. Chicago, June 2003. pp. 459-462.

9. Smyrak B., Knych T., Mamala A., Uliasz P., Jabloński M. A new generation of aluminum enameled winding wires. Wire Journal International, 2012, vol. 45, no. 1, pp. 55-61.

10. Kimura K., Ushirone S., Koyanagi T., Hikita M. PDIV characteristics of twisted-pair of magnet wires with repetitive impulse voltage. IEEE Trans. on Dielectrics and Electrical Ins. Chicago, June 2007. Vol. 14, no. 3, pp. 744-750.

11. Chapman M., Frost N., Bruetsch R. Insulation systems for rotating low-voltage machines. IEEE International Symposium on Electrical Insulation. Chicago, June 2008. pp. 257-260.

12. Hwang D., Lee K., Kim Y., Lee I., Lim T., Kim D. Accessing the insulation characteristics for stator windings of low-voltage induction motors for adjustable-speed drive applications. IEEE Industry Application Conference. Chicago, June 2003. Vol. l, pp. $432-438$.

13. Lahoud N., Faucher J., Malec D., Maussion P. Electrical aging of the insulation of low voltage machines: model definition and test with the design of experiments. IEEE Transactions on Industrial Electronics, 2013, vol. 60, no. 5, pp. 60-67.

14. Leonov A.P., Redko V.V., Soldatenko E.Yu. Estimation of winding insulation resistance to the corona discharges. IOP Conference Series: Materials Science and Engineering, 2014, vol. 66, pp. 1-5.

15. Kimura K., Ushirone S., Koyanagi T., Hikita M. PDIV characteristics of twisted-pair of magnet wires with repetitive impulse voltage. IEEE Trans. on Dielectrics and Electrical Ins. Chicago, June 2007. Vol. 14, no. 3, pp. 744-750. 
16. GOST IEC 60851-5-2011. Provoda obmotochnye. Ch. 5. Elek tricheskie suoystva [State Standard IEC 60851-5-2011. Magnet wires. Test methods. P. 5. Electrical properties]. Moscow, Standartinform Publ., 2014. 19 p.

17. Bellomo J.P., Castelan P., Lebey T. The effect of pulsed voltages on dielectric material properties. IEEE Transactions on Dielectrics and Electrical Insulation, 1999, vol. 6, no. 2, pp. 20-26.

18. Borisenko A., Kostikov 0.N., Yakovlev A.I. Okhlazhdenie promyshlennykh elektricheskikh mashin [Cooling of industrial electric machines]. Moscow, Energoatomizdat Publ., 1983. 296 p.

19. Smirnov G.V. Magnetodielectric composition, its properties and application in resource-saving technology of impregnation of windings of electrical products. Electrical Equipment: operation and repair, 2018, no. 12, pp. 55-69. In Rus.

20. Smyrak B., Knych T., Mamala A., Uliasz P., Jabloński M. A new generation of aluminum enameled winding wires. Wire Journal International, 2012, vol. 45, no. 1, pp. 55-61.

21. Prasad A., Prasad K. Effective permittivity of random composite media: a comparative study. Physica, 2007, vol. 396, no. 11, pp. 132-137.

22. Pokholkov Yu.P., Besperstov P.P., Pykhtin V.V. Issledovanie vliyaniya tekhnologicheskogo protsessa izgotovleniya obmotok na defektnost vitkovoy izolyatsii asinkhronnykh dvigateley [Study of the influence of technological process of manufacturing the windings on the deficiency of turn insulation of induction motors]. Bulletin of the Tomsk Polytechnic Institute, 1975, vol. 222, pp. 52-65.

23. Kondrat'eva G.N., Kuznetsov I.N. Sravnitelnaya otsenka koeffitsientov zapolneniya paza propitochnym sostavom opredelennykh razlichnymi metodami [Comparative evaluation of the fill factor of the groove of the impregnating composition defined by different methods]. Technology of electrical production, 1981, no. 12, pp. 14-16.

24. Dudkin A.N. Razrabotka metodov otsenki tekhnologicheskogo protsessa propitki obmotok asinkhronnykh dvigateley. Dis. Kand. nauk [Development of methods for evaluating technological process of impregnation of the windings of induction motors. Cand. Diss.]. Tomsk. $1980.163 \mathrm{p}$.

25. Smirnov G.V., Smirnov D.G. Capacitive method of quality control of impregnation of windings of electric motors of General industrial application. Electrical Equipment: operation and repair, 2018, no. 3, pp. 68-77. In Rus.
26. Smirnov G.V. Nadezhnost izolyatsii obmotok elektrotekhnicheskikh izdely [Reliability of winding insulation in electrical products]. Tomsk, Tomsk State University Press, 1990.192 p.

27. Frost N., Chapman M., Bruetsch R. Considerations for rotating low-voltage machine insulation designs. IEEE Insulation, 2008, pp. 571-574.

28. Grubic S., Aller J.M., Lu B., Habetler T.G. A survey on testing and monitoring methods for stator insulation systems of low-voltage induction machines focusing on turn insulation problems. IEEE Transactions on Industrial Electronics, 2008, vol. 55, no. 12 , pp. 4127- 4134 .

29. Halpem E.H. Interaction of varnish with magnet wire enamel. IEEE Transactions on Electrical Insulation, 1967, vol. 2, no. 3, pp. 141-145.

30. Khomutov S.O., Kobozev E.V., Semichevsky P.I. Povycshenie effektivnosti vosstanovlenya isolyatsii elektricheskikh dvigately na osnove kompleksnoy otsenki vosdeystruyushikh faktorov [Improving the efficiency of recovery of insulation of electrical motors based on a comprehensive assessment of influencing factors]. Polzunovskii bulletin, 2009, no. 1-2, pp. 220-229.

31. Smirnov G.V. Quality control of impregnation and drying operations of electric motor windings. Electrical Equipment: operation and repair, 2018, no. 5, pp. 24-36. In Rus.

32. Smirnov G.V. Pooperatsionny kontrol protsessa isgotovleniya obmotok elektritsheskikh maschin [Operational control of producing windings of electric machines]. Moscow, Goryachaya liniya Telekom Publ. house, 2018. 156 p.

33. Smirnov G.V., Smirnov D.G. Sposob opredeleniya koeffitsienta propitki otverzhdaemym polimernym sostavom obmotok elektricheskikh mashin [Method of determining the coefficient of winding impregnation with curable polymer composition in electrical machines]. Patent RF, no. 2521439, 2014.

34. Novitskiy P.V., Sograf I.A. Otsenka pogreschnosti resultatov ismereny [Estimation of errors of measurement results]. Leningrad, Energoatomizdat Publ., 1985. 248 p.

35. Forkmann H. Die rcsulticrcnde warmeleitfahig keit getranker Wicklungcn aus Runddraht niit Lackisolation [Speed of sealed winding made of round wire with paint insulation]. German Electrical Engineering, 1957, vol. 12, no. 11. pp. 533-536.

Received: 30 December 2018.

\section{Information about the authors}

Gennady V. Smirnov, Dr. Sc., professor, director of Research Institute of Electronic Production Equipment and Communication Means, Tomsk State University of Control Systems and Radioelectronics.

Maxim V. Vedyashkin, Cand. Sc., associate professor, National Research Tomsk Polytechnic University. 